\title{
XVII. The bakerian lecture, on some new phænomena of chemical changes produced by electricity, particularly the decomposition of the fixed alkalis, and the exhibition of the new substances which constitute their bases; and on the general nature of alkaline bodies
}

\author{
Humphry Davy Esq. Sec. R. S. M.R.I.A.
}

To cite this article: Humphry Davy Esq. Sec. R. S. M.R.I.A. (1808) XVII. The bakerian lecture, on some new phænomena of chemical changes produced by electricity, particularly the decomposition of the fixed alkalis, and the exhibition of the new substances which constitute their bases; and on the general nature of alkaline bodies, Philosophical Magazine Series 1, 32:126, 101-112, DOI: $10.1080 / 14786440808562770$

To link to this article: http://dx.doi.org/10.1080/14786440808562770

Published online: 18 May 2009.

Submit your article to this journal $\sqsubset$

Џll Article views: 3

Q View related articles ¿ 
On the Decomposition and Composition of the Alkalis. 101 inconsistencies. It is seriously to be hoped, as research has developed abundant examples of antient art, that those examples which contain what is useful, chaste, and elegant, will prevail among a people not less distinguished for their taste than their erudition; and that the architect, true to the genuine purpose of his art, will cousider an Herculaneum and a Pompeii as containing stores whereby his reputation may be raised on surer ground, than on the imitation of forts and towers.

J. R.

XVII. The Bukerian Lecture, on some new Phanomena of Chemical Changes produced by Electricity, particularly the Decomposition of the fixed Alkalis, and the Exhitition of the new Sulstances which constitute their Bases; and on the general Nature of alkaline Bodies. By HumpHRx Davy, Esq., Sec. R.S. M.R.I.A.

[Continued from p. 18.]

\section{On the Properties and Nature of the Basis of Soda.}

$T_{\text {HE basis of soda, as I have already mentioned, is a solid }}$ at common temperatures. It is white, opaque, and when examined under a film of naphtha has the lustre and general appearance of silver. It is exceedingly malleable, and is much softer than any of the common metallic substances. When pressed upon by a platina blade, with a small force, it spreads into thin leaves, and a globule of the $\frac{1}{10}$ th or $\frac{1}{1}$ th of an inch in diameter is easily spread over a surface of a quarter of an inch*, and this property does not diminish when it is cooled to $32^{\circ}$ Fahrenheit.

It conducts electricity and heat in a similar manner to the basis of potash; and small globules of it inflame by the voltaic electrical spark, and burn with bright explosions.

Its specific gravity is less than that of water. It swims in oil of sassafras of $1 \cdot 096$, water being one, and sinks in

* Globules may be easily made to adhere and form one mass by strong pressure : so that the property of welding, which belongs to iron and platina at a white heat only, is possessed by this substance at common temperatures. 
naphtha of specific gravity $\cdot 861$. This circumstance enabled me to ascertain the point with precision. I mixed together oil of sassafras and naphtha, which combine very perfectly, observing the proportions till I had composed a fluid, in which it remained at rest above or below; and this fluid consisted of nearly twelve parts naphtha, and five of oil of sassafras, which gives a specific gravity to that of water, nearly as nine to ten, or more accurately as $\cdot 9348$ to 1 .

The basis of soda has a much ligher point of fusion than the basis of potash ; its parts begin to lose their cohesion at about $120^{\circ}$ Fahrenheit, and it is a perfect fluid at about $180^{\circ}$, so that it readily fuses under boiling naphtha.

I have not yet been able to ascertain at what degree of heat it is volatile; but it remains fixed in a state of ignition at the point of fusion of plate glass.

The chemical phænomena produced by the basis of soda, are analogous to those produced by the basis of potash; but with such characteristic differences as might be well expected.

When the basis of soda is exposed to the atmosphere, it immediately tarnishes, and by degrees becomes covered with a white crust, which deliquesces much more slowly than the substance which forms on the basis of potash. It proves, on minute examination, to be pure soda.

The basis of soda combines with oxygen slowly, and without luminous appearance at all common temperatures; and when heated, this combination becomes more rapid; but no light is emitted till it has acquired a temperature nearly that of ignition.

The flame that it produces in oxygen gas is white, and it sends forth bright sparks, occasioning a very beautiful effect; in common air, it burns with light of the colour of that produced during the combustion of charcoal, but much brighter.

The basis of soda when heated in hydrogen seemed to have no action upon it. When introduced into oxymuriatic acid gas, it burnt vividly with numerous scintillations of a bright red colour. Saline matter was formed in this combustion, which, as might have been expected, proved to be muriate of soda. 
Its operation upon water offers most satisfactory evidence of its nature. When thrown upon this fluid, it produces a violent effervescence, with a loud hissing noise; it combines with the oxygen of the water to form soda, which is dissolved, and its hydrogen is disengaged. In this operation there is no luminous appearance; and it seems probable that even in the nascent state hydrogen is incapable of combining with it*.

When the basis of soda is thrown into hot water, the decomposition is more violent, and in this case a few scintillations are generally observed at the surface of the fiuid; but this is owing to small particles of the basis, which are thrown out of the water sufficiently heated, to burn in passing through the atmosphere. When, however, a globule is brought in contact with a small particle of water, or with moistened paper, the heat produced (there being no medium to carry it off rapidly) is usually sufficient for the accension of the basis.

The basis of soda acts upon alcohol and ether precisely in a similar manner with the basis of potash. The water that they contain is decomposed; soda is rapidly formed, and hydrogen disengaged.

The basis of soda, when thrown upon the strong acids, acts upon them with great energy. When nitrous acid is employed, a vivid inflammation is produced; with muriatic and sulphuric acid, there is much heat generated, but no light.

When plunged, by proper means, beneath the surface of the acids, it is rapidly oxygenated; soda is produced, and the other educts are similar to those generated by the action of the basis of potash.

With respect to the fixed and volatile oils and naphtha in their different states, there is a perfect coincidence between the effects of the two new substances, except in the difference of the appearances of the saponaceous compounds formed: those produced by the oxidation and combination

* The more volatile metals only seem capuble of uniting with hydrogen; 3 circumstance presenting an analogy. 
of the basis of soda being of a darker colour, and apparently less soluble.

The basis of soda, in its degrees of oxidation, has precisely similar habits with the basis of potash.

When it is fused with dry soda, in certain quantities, there is a division of oxygen between the alkali and the base; and a deep brown fluid is produced, which becomes a dark gray solid on cooling, and which attracts oxygen from the air, or which decomposes water, and becomes soda.

The same body is often formed in the analytical processes of decomposition, and it is generated when the basis of soda is fused in tubes of the purest plate glass.

There is scarcely any difference in the visible phænomena of the agencies of the basis of soda, and that of potash on sulphur, phosphorus, and the metals.

It combines with sulphur in close vessels filled with the vapour of naphtha with greal vividness, with light, heat, and often with explosion from the vaporization of a portion of sulphur, and the disengagement of sulphuretted hydrogen gas. The sulphuretted basis of soda is of a deep gray colour.

The phosphuret has the appearance of lead, and forms phosphate of soda by exposure to air, or by combustion.

The basis of soda in the quantity of $\frac{1}{4}$, renders mercury a fixed solid of the colour of silver, and the combination is attended with a considerable degree of beal.

It makes an alloy with tin, without changing its colour, and it acts upon lead and gold when heated. I have not examined its habitudes with any other metals, but in its state of alloy it is soon converted into soda by exposure to air, or by the action of water, which it decomposes with the evolution of hydrogen.

The amalgam of mercury and the basis of soda seems to form triple compounds with other metals. I have tried iron and platina, which I am inclined to believe remain in combination with the mercury, when it is deprived of the new substance by exposure to air.

The amalgam of the basis of soda and mercury likewise combines 
combines with sulphur, and forms a triple compound of a dark gray colour.

\section{On the Proportions of the peculiar Bases and Oxygen in Potash and Soda.}

The facility of combustion of the bases of the alkalis, and the readiness with which they decomposed water, offered means fully adequate for determining the proportions of their ponderable constituent parts.

I shall mention the general methods of the experiments, and the results obtained by the different series, which approach as near to each other as can be expected in operations performed on such small quantities of materials.

For the process in oxygen gas, I employed glass tubes containing small trays made of thin leaves of silver or other noble metals, on which the substance to be burnt, after being accurately weighed or compared with a globule of mercury, equal in size *, was placed : the tube was small at one end, curved, and brought to a fine point, but suffered to remain open ; and the other end was fitted to a tube communicating with a gasometer, from which the oxygen gas was introduced, for neither water nor mercury could be used for filling the apparatus. The oxygen gas was carried through the tube till it was found that the whole of the common air was expelled. The degree of its purity was ascertained by suffering a small quantity to pass into the mercurial apparatus. The lower orifice was then hermetically sealed by a spirit lamp, and the upper part drawn out and finally closed, when the aperture was so small, as to render the temperature employed incapable of materially infuencing the volume of the gas; and when the whole arrangement was made, the combination was effected by applying heat to the glass in contact with the metallic tray.

In performing these experiments many difficulties oc-

* When the globules were very small, the comparison with mercury, which may be quickly made by means of a micrometer, was generally employed as the means of ascertaining the weight : for in this case the globule could be immediately introduced into the tube, and the weight of mercury ascertained at leisure. 
curred. When the flame of the lamp was immediately brought to play upon the glass, the combustion was very vivid, so as sometimes to break the tube; and the alkali generated partly rose in white fumes, which were deposited upon the glass.

When the temperature was slowly raised, the bases of the alkalis acted upon the metallic tray and formed alloys, and in this state it was very difficult to combine them with their full proportion of oxygen; and glass alone could not be employed on account of its decomposition by the alkaline bases; and porcelain is so bad a conductor of heat, that it was not possible to raise it to the point required for the proccss, without softening the glass.

In all cases the globules of the alkaline bases were carefully freed from naphtha before they were introduced; of course a slight crust of alkali was formed before the combustion, but this could not materially affect the result; and when such a precaution was not used, an explosion generally took place from the vaporization and decomposition of the film of naphtha surrounding the globule.

After the combustion, the absorption of gas was ascertained, by opening the lower point of the tube under water or mercury. In some cases the purity of the residual air was ascertained, in others the alkali formed in the tray was weighed.

From several experiments on the synthesis of potash by combustion, I shall select two, which were made with every possible attention to accuracy, and under favourable circumstances, for a mean result.

In the first experiment 0.12 grains of the basis were employed. The combustion was made upon platina, and was rapid and complete; and the basis appeared to be perfectly saturated, as no disengagement of bydrogen took place when the platina tray was thrown into water. The oxygen gas absorbed equalled in volume 190 grain measures of quicksilver; barometer being at 29.6 inches, thermometer $62^{\circ}$ Fahrenheit ; and this reduced to a temperature of $60^{\circ}$ Fahrenheit, and under a pressure equal to that indicated by 30 inehes, 
inches*, would become 186.67 measures, the weight of which would be about $\cdot 0131$ grains troy $\dagger$, but $\cdot 0184: \cdot 1384:$ : $13.29: 100$; and according to this estimation 100 parts of potash will consist of 86.7 basis, and 13.3 oxygen nearly.

In the second experiment 07 grains of the basis absorbed at temperature $63^{\circ}$ of Fahrenheit, and under pressure equal to 30.1 barometer inches, a quantity of oxygen equal in volume to 121 grain measures of mercury, and the proper corrections being made as in the former case, this gas would weigh 01189 grains.

But as $\cdot 07+\cdot 01189=\cdot 08189: 07:: 100: 85 \cdot 48$ nearly, and 100 parts of potash will consist of 85.5 of basis and 14.5 of oxygen nearly. And the mean of the two experiments will be 86.1 of basis to 13.9 of oxygen for 100 parts.

In the most accurate experiment that I made on the combustion of the basis of soda 08 parts of the basis absorbed a quantity of oxygen equal to 206 grain measures of mercury; the thermometer being at $56^{\circ}$ Fabrenheit; and the barometer at 29.4 ; and this quantity, the corrections being made as before for the mean temperature and pressure, equals about $\cdot 02$ grains of oxygen.

And as $\cdot 08+\cdot 02=\cdot 10: \cdot 08,:: 100: 80$, and 100 parts of soda according to this estimation will consist of 80 basis to 20 of oxygen.

In all cases of slow combustion, in which the alkalis were not carried out of the tray, I found a considerable increase of weight; but as it was impossible to weigh them except in the atmosphere, the moisture attracted rendered the results doubtful; and the proportions from the weight of the oxygen absorbed are more to be depended on. In the experiments in which the processes of weighing were most speedi,

* In the correction for temperature, the estimations of Dalton and Gay Lussac are taken, which make gases expand about $\frac{1}{4 \frac{1}{0}}$ of the primitive volume for pvery degree of Fahrenheit.

† From experiments that I made in 1799, on the specific gravity of oxygew gas, it would appear that its weight is to that of water as 1 to 748 , and to that of quicksilver as 1 to 10142. Researches Chem, and Phil. p. 9; and with this estimation, that deducible from the late accurate researches of Messrs. Allen and Pepys on the Combustion of the Diamond almost precisely agrees. Phil. Trans, 1807, p. 275. 
ly performed, and in which no alkali adhered to the tube, the basis of potash gained nearly two parts for ten, and that of soda between three and four parts.

The results of the decomposition of water by the bases of the alkalis were much more readily and perfectly obtained than those of their combustion.

To check the rapidity of the process, and, in the case of potash, to prevent any of the basis from being dissolved, I employed the amalgams with mercury. I used a known weight of the bases, and made the amalgams under naphtha, using about two parts of mercury in volume to one of basis.

In the first instances I placed the amalgams under tubes filled with naphtha, and inverted in glasses of naphtha, and slowly admitted water to the amalgam at the bottom of the glass; but this precaution I soon found unnecessary, for the action of the water was not so intense but that the hydrogen gas could be wholly collected.

I shall give an account of the most accurate experiments made on the decomposition of water by the bases of potash and soda.

In an experiment on the basis of potash conducted with every attention that $I$ could pay to the minutia of the operations, hydrogen gas, equal in volume to 298 grains of mercury, were disengaged by the action of $\cdot 08$ grains of the basis of potash which had been amalgamated with about three grains of mercury. The thermometer at the end of the process indicated a temperature of $56^{\circ}$ Fahrenheit, and the barometer an atmospheric pressure equal to $29^{\circ} 6$ inches.

Now this quantity of hydrogen* would require for its combustion a volume of oxygen gas about equal to that occupied by 154.9 grains of mercury, which gives the weight of oxygen required to saturate the $\cdot 08$ grains of the basis of potash at the mean temperature and pressure nearly 0151 grains. And $\cdot 08+\cdot 0151=\cdot 0951: \cdot 08:: 100: 84 \cdot 1$ nearly.

And according to these indications 100 parts of potash consist of about 84 basis and 16 oxygen. 
In an experiment on the decomposition of water by the basis of soda, the mercury in the barometer standing at 30.4 inches, and in the thermometer at $52^{\circ}$ Fahrenheit, the volume of hydrogen gas evolved by the action of 054 grains of basis equalled that of 326 grains of quicksilver. Now this at the mean temperature and pressure would require for its conversion into water, .0172 of oxygen, and $\cdot 054+$ $\cdot 0172=\cdot 0712: \cdot 054:: 100: 76$ nearly; and according to these indications, 100 parts of soda consist of nearly 76 basis, and 24 oxygen.

In another experiment made with very great care, $\cdot 052$ of the basis of soda were used; the mercury in the barometer was at 29.9 inches, and that in the thermometer at $58^{\circ} \mathrm{Fah}$ renheit. The volume of hydrogen evolved was equal to that of 302 grains of mercury; which would demand for its saturation by combustion, at the mean temperature and pressure, 01549 grains of oxygen; and 100 parts of soda, according to this proportion, would consist nearly of 77 basis, and 23 oxygen.

The experiments which have been just detailed, are those in which the largest quantities of materials were employed; I have compared their results, however, with the results of several others, in which the decomposition of water was performed with great care, but in which the proportion of the bases was still more minute : the largest quantity of oxygen indicated by these experiments was, for potash 17 , and for soda 26 parts in 100, and the smallest 13, and 19; and comparing all the estimations, it will probably be a good approximation to the truth, to consider potash as composed of about six parts basis and one of oxygen; and soda, as consisting of seven basis and two oxygen.

VII. Some general Observations on the Relations of the Bases of Potash and Soda to other Bodies.

Should the bases of potash and soda be called metals? The greater number of philosophical persons to whom this question has been put, have answered in the affirmative. They agree with metals in opacity, lustre, malleability, conducting 
ducting powers as to heat and electricity, and in their qual:ties of chemical combination.

Their low specific gravity does not appear a sufficient redson for making them a new class; for amongst the thetals themselves there are remarkable differences in this respect, platina being nearly four times as heavy as telluriuth*; and in the philosophical division of the classes of bodies, the analogy between the greater number of properties must always be the foundation of arrangement.

On this idea, in naming the bases of potash and soda, it will be proper to adopt the termination which, by common consent, has been applied to other newly discovered thetals, and which, though originally Latin, is now naturalized in our language.

Potasium and sodium are the names by which I have ventured to call the two new substances: and whatever changes of theory, with regatd to the composition of bodies, maty hereafter take place, these terms can scarcely express an error; for they may be considered as implying simply the metals produced from potasii and soda. I have consulted with many of the most eminent scientific persons in this country, upon the methods of derivation, and the one I have adopted has been the one most generally approved. It is perhaps more significant than elegant. But it was not possible to found names upon specific properties not common to both; and though a name for the basis of soda might have been borrowed from the Greek, yet an analogous one could not have been applied to that of potash, for the antients do not seem to have distinguished between the two alkalis.

The more caution is necessary in avoiding any theoretical expression in the terms, because the new electro-chemical phænomena that are daily becoming disclosed, seem di-

* 'Tellurium is not much more than six times as heary as the basis of soda. There is great teason to believe that bodies of a similar chemical nature to the bases of potash and soda will be found of intermediate specific gravities between them and the lightest of the common metals. Of this subject I shall treat again in the text in some of the following pages. 
stinctly to show that the mature time for a complete generatization of chemical facts is yet far distant; and though, in the explanations of the various results of experiments that have been detailed, the antiphlogistic solution of the phanomena has been uniformly adopted, yet the motive for employing it bas been rather a sense of its beauty and precision, than a conviction of its permanency and truth.

The discovery of the agencies of the gases destroyed the hypothesis of Stahl. The knowledge of the powers and effects of the ethereal substances may at a future time possibly act a similar part with regard to the more refined and ingenious hypothesis of Lavoisier; but in the present state of our knowledge, it appears the best approximation that hus been thade to a perfect logic of chemistry.

Whateter fulure changes may take place in theory, there stetins however every reason to believe that the metallic bases of the alkalis, and the common metals, will stand in the same arrangement of substances; and as yet we have no good reasons for assuming the compound nature of this class of bodies *.

The experiments in which it is said that alkalis, metallic oxides, and earths may be formed from air and water alone, in processes of vegetation, have been always made in an inconclusive manner $\uparrow$; for distilled water, as I have endeavoured

- A phlogistic chemical theory might certainly be defended, on the idea that the metals are compounds of certain unknown bases with the same matter as that existing in hydrogen; and the metallic oxides, alkatis and acids compounds of the same bases with water; - but in this theory more unknown principles would be sssumed than in the generally received theory. It would be less elegant and less distinct. In my first experiments on the distillation of the basis of potash finding hydrogen generally produced, I was led to conpare the phlogistic hypothesis with the new facts, and I found it fully adequate to the explanation. More delicate researches however afterwards proved that in the cases when inflammable gases appeared, water, or some body in which hydrogen is admitted to exist, was present.

t The explanation of Van Helmont of his fact of the production of eatth in the growth of the willow, was completely overturned by the researches of Woodward. Phil. Trans. vol, xxi. p. 193.

The conclusions which M. Braconnot has very lately drawn from his ingenious experiments, Annales de Chimie, Fevrier 1807, p. 187, are rendered of little avail in consequence of the circumstances stated in the tert. In the only 


\section{On the Decomposition and Composition of the Alkalis.}

voured to show *, may contain both saline and metallic impregnations; and the free atmosphere almost constantly holds in mechanical suspension solid substances of various kinds.

In the common processes of Nature, all the products of living beings may be easily conceived to be elicited from known combinations of matter. The compounds of iron, of the alkalis, and earths, with mineral acids, generally abound in soils. From the decomposition of basaltic, porphyritic $t$, and granitic rocks, there is a constant supply of earthy alkaline and ferruginous materials to the surface of the earth. In the sap of all plants that have been examined, certain neutrosaline compounds, containing potash, or soda, or iron, have been found. From plants they may be supplied to animals. And the chemical tendency of organization seems to be rather to combine substances into more complicated and diversified arrangements, than to reduce them into simple elements.

case of vegetation in which the free atmosphere was excluded, the seeds grew in white sand, which is stated to have been purified by washing in muriatic acid; but such a process was insufficient to deprive it of substances which might afferd carbon, or various inflammable matters. Carbonaceous matter exists in several stones which afford a whitish or grayish powder; and when in a stone the quantity of carbonate of lime is very small in proportion to the other earthy ingredients, it is scarcely acted on by acids.

* Bakerian Lecture, 1806, page 8.

I In the year 1804, for a particular purpose of geological inquiry, I made an analysis of the porcelain clay of St. Stevens, in Cornwall, which results from the decomposition of the feldspar of fine-grained granite. I could not detect in it the smallest quantity of alkali. In making some experiments on specimens of the undecompounded rock taken from beneath the surface, there were evident indications of the presence of a fixed alkali, which seemed to be potash. So that it is very probable that the decomposition depends on the operation of water and the carbonic acid of the atmosphere on the alkali forming a constituent part of the crystalline matter of the feldspar, which may disintegrate from being deprived of it.

[To be continued.] 